\title{
Imprensa, gênero e cultura científica na década de 1960: entrevista com Eulina Cavalcante, do jornal News Seller
}

\author{
The press, gender, and scientific culture in the 1960s: an interview \\ with Eulina Cavalcante, journalist for the newspaper News Seller
}

Entrevista com:

Eulina Cavalcante de Almeida

Professora.

Rua Wenceslau Brás, 44/91

09541-200 - São Caetano do Sul $\mathrm{SP}$ - Brasil

eulina.almeida@uol.com.br

Concedida a

\section{Clara Guimarães}

Mestre em Ensino, História, Filosofia das Ciências e Matemática.

Rua Peixoto Gomide 51/64

01409-001 - São Paulo - SP - Brasil claragui@gmail.com

\section{Graciela de Souza Oliver}

Professora, Centro de Ciências Naturais e Humanas/Universidade Federal do ABC.

Av. dos Estados, 5001

09210-580 - Santo André - SP Brasil

graciela.oliver@ufabc.edu.br
GUIMARÃES, Clara; OLIVER, Graciela de Souza. Imprensa, gênero e cultura científica na década de 1960: entrevista com Eulina Cavalcante, do jornal News Seller. História, Ciências, Saúde - Manguinhos, Rio de Janeiro, v.22, n.4, out.-dez. 2015, p.1441-1449.

Resumo

Entrevista realizada com a jornalista Eulina Cavalcante de Almeida, editora dos suplementos femininos do jornal News Seller (ABC Paulista) na década de 1960. Eulina foi responsável por introduzir questões femininas e científicas para as mulheres leitoras do jornal; tinha na ciência uma das bases para sua escrita e trazia informações científicas, principalmente na área da saúde, para as leitoras. Na década de 1960 houve um aumento no Brasil do letramento científico da população, e a atuação de Eulina ia ao encontro desse movimento. O suplemento feminino do News Seller foi de grande importância para a divulgação científica no ABC Paulista.

Palavras-chave: jornais; ditadura militar; difusão científica; imprensa feminina.

\section{Abstract}

The article offers an interview with journalist Eulina Cavalcante de Almeida, editor of the woman's section of the ABC Paulista newspaper News Seller in the 1960s. Almeida was responsible for introducing women's and scientific issues to the paper's female readers. Science formed one of the foundations of her writing as she offered her women readers scientific information, especially in the area of health. In the 1960s, the level of scientific literacy in Brazil rose and Almeida's work dovetailed with this trend. The woman's section of News Seller played a valuable role in science communication in the ABC Paulista.

Keywords: newspapers; military dictatorship; science communication; women's press. 
Sta entrevista com Eulina Cavalcante de Almeida foi realizada no dia 6 de dezembro de
2013. Natural de Porto Feliz (SP), Eulina foi para Santo André (SP) ainda pequena e ali fez carreira como jornalista. Foi editora do suplemento do "Entre Nós... as Mulheres" e o "Ela", entre 1964 e 1969, no jornal News Seller do ABC Paulista. Nesta entrevista a editora comenta um pouco sobre sua vida e o trabalho no jornal.

O trabalho de Eulina era direcionado ao público feminino e tinha dois objetivos principais: tratar de questões femininas e realizar a difusão científica. O jornal contava com ampla distribuição na região, chegando a duzentos mil exemplares todo domingo. Na pesquisa intitulada "Mulher, ciência e tecnologia: uma análise feminista do jornal News Seller", ${ }^{1}$ financiada pela Fapesp, foi realizado um levantamento das matérias da área de saúde escritas pela jornalista e publicadas em 1967. Nessa pesquisa concluímos que todas utilizavam informações científicas. As matérias faziam referência a pesquisas científicas e à ciência aplicada ao cotidiano, principalmente sobre o cuidado com o corpo e com os filhos. As informações científicas eram geralmente publicadas nas páginas 2 e 5 do suplemento feminino "Ela", um encarte com oito páginas. O suplemento "Ela" do News Seller, único na região do ABC Paulista, concorria diretamente com o jornal Estadão [O Estado de S.Paulo].

Segundo Daniela Jacobucci, ${ }^{2}$ na década de 1960 os divulgadores da ciência e os cientistas estavam muito preocupados com a popularização do ensino de ciências. O News Seller seguia essa tendência, pois fazia um trabalho de divulgação e difusão científica desde a sua fundação. Em relação ao gênero, essa década foi muito significativa para divulgação do feminismo e das questões direcionadas à mulher, e o News Seller teve um papel fundamental na vida das mulheres da região não só por ser o jornal mais lido e por ter seções específicas para elas, mas por trazer discussões sobre emancipação feminina, além de usar argumentos científicos para afirmar que apesar das diferenças biológicas as mulheres eram tão capazes quanto os homens. Esse discurso permeava a educação de seus filhos, sua sexualidade e inserção no mercado de trabalho. A presente entrevista articula tais aspectos à história do jornalismo e das ciências.

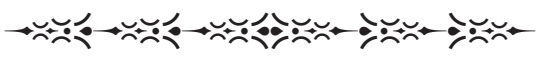

Gostaria de saber como você chegou ao News Seller.

Eu trabalhava em uma empresa chamada International Harvester. Era uma fábrica de caminhões que tinha em Santo André, e, como sempre gostei de escrever, eu fazia o jornalzinho da empresa, no tempo do mimeógrafo, sabe, muito rudimentar, pois não existia computador. Então datilografávamos todo o material e depois imprimíamos no mimeógrafo. Tinha uma seção de esportes, uma página feminina, que eu mesma escrevia, mas a seção de esportes era um colega quem fazia. Um dia, eu estava com um jornalzinho desses na bolsa e fui ao Clube Primeiro de Maio, num dia de semana. O clube não tinha nada, mas passei lá, pois tinha uma amiga que frequentava muito o lugar. Nós

\footnotetext{
${ }^{1}$ Fapesp - processo número: 2013/04602-5.

2 JACOBUCCI, Daniela F.C. A formação continuada de professores em centros e museus de ciências no Brasil. Tese (Doutorado em Educação) - Faculdade de Educação, Universidade Estadual de Campinas, Campinas. 2006.
} 
combinamos um encontro no clube para conversar um pouco, mas por coincidência estava lá o Edson Danilo Dotto, que era um dos diretores do Diário [Diário do Grande $A B C]$, um dos fundadores. Eu o conhecia de vista, ele já tinha passado por lugares onde eu estava, já tínhamos sido apresentados. Ele me perguntou o que é que eu fazia, falei que trabalhava na International... Peguei um exemplar do jornal e falei para ele: "Olha, esse aqui é um jornalzinho da empresa, muito modesto, praticamente uma brincadeira feita no mimeógrafo, mas tem algumas coisas que eu gosto muito e uma página que eu escrevo". Então, ele disse assim: "Olha, nada é por acaso, eu estou precisando de uma mulher para escrever a página feminina do News Seller". Isso foi em 1962 para 1963; então falei: "Ah, não tenho capacidade para isso, meu trabalho é muito modesto, é coisa de jornalzinho de empresa". Uma página do News Seller... porque o News Seller naquela época era o único jornal, não, tinha outro, tinha o jornal Repórter.

Tinha o Jornal Santo André também.

Isso! Tinha o Repórter e o Jornal Santo André, mas eram muito inferiores ao News Seller, pois o News Seller tinha uma cobertura grande de todo o ABC. Então ele falou assim: "Olha, passa lá na redação, eu vou te apresentar ao redator-chefe, que é o Fausto Polesi, e vocês conversam". E ele levou o tal jornalzinho. Nele, havia um artigo escrito por mim. Então eles me telefonaram e disseram que eu fosse mesmo lá, pois queriam que eu trabalhasse no jornal. Fui conhecer o Fausto, que me falou o seguinte: "Você está muito à frente do que a gente vê em páginas femininas, porque não é só receita, você aborda outros assuntos comportamentais. Sabe, a mulher está conquistando o seu espaço". Os anos 1960 mudaram o mundo, foi a época da liberação feminina, aquela coisa toda. Eles queriam alguém que escrevesse coisas modernas, então eu comecei. Eles me deram plena liberdade

\section{Isso em 1964?}

Não, foi final de 1962, começo de 1963.

\section{Então você começou escrevendo a "Página Feminina"?}

A "Página Feminina" do News Seller... O prédio ainda era na rua Bernardino de Campos, era uma sala. Para você ter uma ideia, havia uma só máquina de escrever. Os redatores precisavam revezar a hora que iam ao jornal, porque só tinha uma máquina, então você tinha hora marcada: ia das cinco às seis [horas], seis às sete [horas]. Mas consegui comprar uma máquina na empresa em que eu trabalhava, pois ela fez uma venda de máquinas usadas, e comprei uma máquina de escrever alemã. Assim eu já levava pronta a minha matéria para o News Seller. E eles me deram ampla liberdade, pois eram pessoas - os quatro fundadores do News Seller - muito abertas, dinâmicas... Pessoas maravilhosas! Eles davam muita força para quem estava começando e fizeram isso comigo. O Fausto Polesi foi uma pessoa muito marcante na minha vida, porque me ensinou muito.

Naquela época, o redator de um jornal não escrevia simplesmente a matéria, ele tinha que ir à oficina fazer a revisão do que tinha escrito. Havia as linotipos, que eram as máquinas que imprimiam aquelas tirinhas de chumbo, depois a página era montada, tinha uma rama... O redator era responsável pela página, então eu tinha que ir à oficina, sujar a mão de 
graxa mesmo e arrumar o que tivesse errado, tirava uma cópia e revisava tudo. Você punha a mão na massa. Não era só ser redatora, você participava da confecção do jornal. Quando o Diário foi inaugurado, ficou mais fácil [iniciou como News Seller e foi rebatizado de Diário do Grande ABC em 1968], pois nós já trabalhávamos naquele prédio grande da rua da Catequese, e a oficina já era lá; assim, não precisávamos ficar nos deslocando para outros lugares onde o jornal era impresso. Era assim, e o Fausto Polesi me ensinou muito, ele me ensinou a diagramar uma página de jornal, que é a estética, o desenho da página. E só essa parte de diagramação já seria uma profissão muito bem remunerada, fora todas as outras coisas que aprendi com ele.

Eu tenho uma dúvida, você trabalhava na "Página Feminina", mas em 1963 ela parou de ser escrita e ficou uma época sem que houvesse publicações para as mulheres.

1963... foi a época de transição para o Diário.

Não, o Diário iniciou em maio de 1968.

Eu fiz o suplemento "Ela" em 1966 e 1967.

E tem uns exemplares no começo de 1968. Mas o golpe foi em 1964; logo depois do golpe, na semana seguinte, iniciou a coluna "Mulher e Lar". Você fazia a "Mulher e Lar" também?

Não.

Então você começou com "Entre Nós... as Mulheres" ou com "Página Feminina?"

"Entre Nós... as Mulheres".

Então, foi 1964. Por isso confundi, pois antes era publicada uma página chamada "Página Feminina" e não tinha o seu perfil. O "Entre Nós" começou em agosto de 1964; antes era o "Mulher e Lar". "O Entre Nós" ficou até 1966; nesse mesmo ano iniciou o "Ela".

Isso! Foi editado em 1966 e 1967, você tem razão. O Diário entrou em 1968, paramos com o suplemento, virando uma página.

E sobre a questão política?

Só poucas vezes o Diário teve problema com a censura. Acontecia assim: nós tínhamos sempre uma poesia ou uma receita de bolo na gaveta. Então eles pediam, pois eu era a editora feminina, que eu arrumasse receita de bolo, pois tinha que passar mesmo pela censura, e quando eles censuravam algum artigo, entrava lá uma receita de bolo no lugar e ninguém entendia por que tinha uma receita no meio de uma página importante que falava de política, que falava de outras coisas, fatos atuais, e aparecia uma receita de bolo. E todo mundo perguntava: mas por que isso? Só não sabiam que era a censura, mas foram poucas as vezes, pois o Diário nunca teve problema.

Quem teve muito problema na época foi o jornal Última Hora, que tinha sucursal em Santo André. O pessoal da redação do News Seller com o pessoal da Última Hora tinha muita amizade, pois nós éramos, vamos dizer assim, uma classe à parte, não havia quase ninguém trabalhando em jornal; os que trabalhavam, tanto do Repórter, quanto do Diário [News Seller até 1968], como os da Última Hora, eram muito amigos. Só não sabíamos que tinha gente da 
Última Hora, como era o caso do jornalista C., ${ }^{3}$ que era muito famoso. Ele se tornou presidente, depois, do Sindicato dos Jornalistas; o C. era muito politizado e de esquerda, e tinha um fotógrafo chamado P., muito nosso amigo, que também era de esquerda. Eles foram presos, torturados, sumiram por um tempo, e fiquei muito assustada, pois eu ligava para redação e todo mundo falava que eles não foram, não sabiam onde estavam e não davam informação. Como eu tinha o telefone do P., liguei e falei com a esposa dele, que me disse: "Olha, ele está preso. Ela falou que não podia comentar, mas que ele estava preso, e a gente também não podia visitar, pois se corria o risco de ser preso por qualquer motivo naquela época. O Diário não teve muito problema não, eles eram apolíticos, não se envolviam em nada. Nós não tivemos nada, mas que foi uma época difícil foi. Você tinha medo de andar na rua, porque havia muitos boatos de que seria feita uma revolução armada, com prisões aleatórias. O povo tinha muito medo do que estava para acontecer, pois tudo era muito novo. Nós não tivemos esse problema. Pisávamos em ovos. Por exemplo, você recebia um convite para fazer uma reportagem de algum lugar, tinha que se informar antes quem é que estava promovendo, por que estava promovendo, pois atrás de um jantar podia ter uma reunião política de esquerda e, se você fosse pego lá, seria preso em flagrante. Então precisávamos tomar esse cuidado, o jornal recomendava muito: "Cuidado, vejam aonde vocês vão, se informem antes, quem está promovendo, por que está promovendo", mas não tivemos grandes problemas.

Foram assim os anos, principalmente na ocasião em que atuei como redatora do Ela. Foi uma época de grandes mudanças, sobretudo para a mulher. Foi assim quando estourou tudo, saiu a minissaia... Para você ter uma ideia, teve uma coisa muito engraçada, você deve ter visto essa reportagem no Ela. Quando saiu a minissaia, aquilo foi um escândalo. Eu fiz uma reportagem com pessoas da sociedade sobre o que achavam da minissaia e entrevistei inclusive um delegado de polícia na época. Perguntei a ele se teria algum problema as mulheres usarem minissaia, se elas poderiam ser presas por causa do decoro, aquela coisa toda. Aí ele falou que não, que não havia legislação para isso, que a mulher não poderia ser presa, mas que pelos bons costumes, pela valorização da família, as mulheres não deveriam exagerar, que a saia devia ser usada no joelho. Na época foi uma coisa tão engraçada, imagine um delegado de polícia opinando sobre a minissaia. E aí entrevistei uma senhora que era considerada uma das mulheres mais elegantes do ABC. Perguntei sobre a minissaia, o que ela achava, e ela disse que usaria, e era uma senhora casada e com filhos grandes. Ela falou que estava louca para usar a minissaia. ... Me parece que entrevistei um padre também. Você vê, imagina uma coisa tão... hoje uma coisa tão... a mulherada está aí quase nua, não é? E naquela época a minissaia foi um escândalo, um verdadeiro escândalo na sociedade.

Mas, além disso, uma questão fundamental que é marcante no suplemento "Ela" é a introdução de elementos científicos. No "Entre Nós" tinha um pouco, como em um editorial sobre educação das crianças e o uso de termos como: psicólogos, pedagogos para sustentar o discurso, mas com o "Ela" em 1966, essa característica diminui, e as matérias giram em torno de temas como beleza, moda, etiqueta. Quando o suplemento foi reformulado, em 1967, as matérias sobre questões científicas passaram a ser

${ }^{3}$ A entrevistada preferiu ocultar a identidade dos jornalistas C. e P. 
muito importantes, novamente. Naquele mesmo momento, o suplemento começou a trazer também matérias sobre atualidades. Como funcionava essa questão do uso da ciência nas matérias?

Eu sempre me interessei muito por ciência, então eu procurava ler tudo que podia e encontrava. A gente lia outros jornais, revistas, procurava se atualizar muito. Quando tinha um artigo de cunho científico do meu interesse, eu abordava, pois acho que a ciência está acima de tudo, não tem por onde. E eu gostava muito desse aspecto científico das coisas, das grandes novidades. Você vê, a vacina Sabin surgiu na década de 1960, não lembro o ano, mas foi na década de 1960; o homem chegou à Lua nos anos 1960, tinha os Beatles nos anos 1960. Foi uma década fervilhante. Uma verdadeira revolução, então as pessoas tinham que ter uma mentalidade muito avançada para poder escrever, e o Fausto Polesi, que era o diretor da redação, brincava comigo assim: "Tinha que ser uma aquariana para escrever o suplemento Ela". Pois se dizia que a mulher aquariana estava 100 anos à frente do seu tempo. Ele dizia assim: "Tinha que ser uma aquariana para escrever isso, pois você é avançada demais, você escreve umas coisas muito modernas. Cuidado, hein, você está feminista demais". Eles brincavam comigo. Quando foi inaugurado o prédio do Diário lá na Catequese, eu ficava na sala de baixo, ao lado da oficina, e os diretores tinham uma escada que ia para o andar de cima, que era a sala da diretoria. Quando eles chegavam, eu já estava lá na minha máquina escrevendo, e cada diretor que passava dizia: "Como é, está falando muito mal dos homens? Está 'metendo o pau' nos homens?" A brincadeira era essa, que eu era muito feminista, mas não é, foi a mudança que houve, foi um boom.

Mas tinha pressão de alguma forma em relação às matérias, que elas tinham que ser mais ou menos de determinada forma?

Não, eu escrevia o que queria, passava tudo pelo crivo do chefe da redação. A gente escrevia os artigos e depois entregava para ele, que fazia a diagramação da página e mandava para a oficina. A partir do momento em que fosse para a oficina, a responsabilidade era minha, aí eu tinha que revisar, mudar lá o que tinha que mudar. Eu chamava o chefe da oficina e falava: "Olha, isso aqui está errado, tem que corrigir, coisa e tal". A responsabilidade era minha, mas tudo passava pelo crivo do chefe da redação. Eu nunca tive um artigo recusado, nunca barraram alguma coisa que eu escrevi. Era um clima de muita amizade, de muita brincadeira, no Diário. Eu era a única mulher em uma redação de quarenta homens, para você ter uma ideia. Fizeram uma sala lá em cima, no prédio do Diário, não era aquele prédio da frente, pois no início era um lá no fundo. Eu ficava em uma sala com quarenta homens fumando. Alguns dias eu passava mal, tinha que sair e ir embora, pois não aguentava.

Você poderia me falar um pouco mais do "Entre Nós", quando começou, e, depois, sobre a transição para o "Ela" e o que motivou essa transição?

Olha, o "Entre Nós... as Mulheres" era uma página que fazia muito sucesso na época, muito sucesso. O Diário [News Seller] fez uma pesquisa, e era a sessão mais lida do jornal. Eles fizeram essa pesquisa justamente porque estavam para lançar o Diário e queriam saber que rumo tomar, e a resposta foi unânime. O resultado me surpreendeu muito: os homens liam muito. Foi considerada a sessão mais lida do Diário, então eles me convidaram para editar o suplemento. Achavam que estava na hora de o jornal ter um suplemento, mas demorou até 
ter o Diário. Eles amadureceram a ideia mais ou menos uns cinco anos para lançar. Eu lancei, na verdade, o suplemento bem antes do Diário, dois anos antes. E quando veio o Diário surgiu um problema técnico: não dava para editar um jornal todos os dias e mais um suplemento. Foi um problema puramente técnico, e eles me deram uma página...

O "Ela" ficou no domingo e em notinhas diárias. E em relação à reformulação do "Ela", pois ele era de um jeito e depois, em 1967, foi reformulado, o que foi que motivou essa reformulação?

Não foi nada de importante, a gente quis modernizar cada vez mais. Eu queria melhorar, não foi assim um fato muito determinante, foi uma reformulação interna, porque a gente queria. A ideia, no começo, era ampliar e depois, por causa do Diário (já estavam se preparando para lançar o Diário), eles não aumentaram, mas a ideia era essa, modernizar cada vez mais, ficar mais bonito, porque seria um chamariz para o Diário; e, no fim, o coitado foi prejudicado, porque não dava para editar os dois. As máquinas do Diário na época não comportavam, e o Ela era praticamente um jornal à parte, com muito colorido, muitas fotos. Naquela época era muito difícil, pois para uma foto, por exemplo, que você publicava no jornal tinha que ser feito um clichê. Isso não tinha aqui quem fizesse, não tinha em Santo André, precisava ir para São Paulo, para uma clicheria, para fazer o clichê daquela foto. O officeboy levava de manhã e ia buscar de tarde, chegava aqui à noite, e só no outro dia eu ia ter o clichê da foto. Imagina, hoje é tudo computadorizado, você joga a foto ali com a maior facilidade. Naquela época não, era muito difícil, pois o jornal era artesanal e havia muita dificuldade. Era uma coisa que os jornais todos precisavam, todo jornal tinha que ter uma clicheria. Dava tanto dinheiro, e até hoje não entendo como um cidadão de Santo André não quis ganhar dinheiro com isso. Nunca teve uma clicheria em Santo André.

E eu gostava de fotos bonitas. Naquele tempo a gente tinha os desfiles da Rhodia, que fazia desfiles de moda, lançava moda; tinha o Dener e o Clodovil, que faziam muita coisa bonita. O departamento de imprensa, tanto da Rhodia como do Dener, me fornecia muitas fotos bonitas, e eu brigava porque queria a foto inteira. Não sei se você percebeu que tem fotos bem grandes de modelos da Rhodia. Na época havia umas modelos muito bonitas, uma delas está na Rede Globo até hoje, Mila Moreira; ela era manequim da Rhodia naquela época. Eu fazia questão de tudo moderno, não queria nada igual aos outros, então, na verdade, o Ela competia com o suplemento feminino do Estadão, de igual para igual. Até a redatora era minha amiga, a Maria Lucia Fragata Mesquita. A gente trocava ideia por telefone, conversava, mas éramos concorrentes. Muita gente na época preferia assinar o News Seller por causa do suplemento feminino, porque era no domingo e concorria com o suplemento do Estadão.

E essa relação entre tecnologia e o News Seller, por exemplo: a GM, a Rhodia. No jornal havia uma coluna chamada "GMI"; qual o peso da tecnologia no jornal?

Eu acredito até que nem era o peso da tecnologia, era uma questão comercial mesmo, tudo matéria paga, menos no suplemento feminino, a minha parte não tinha matéria paga. Esse trabalho que eu fazia de divulgar os desfiles da Rhodia era uma coisa espontânea que eu queria fazer; eu ia lá, aliás, nem fotografava, era o próprio fotógrafo da Rhodia. Eles mandavam aquilo pronto para a gente, vinha o nome da manequim, quem tinha feito a roupa, e o departamento de imprensa divulgava. Então, como a Rhodia era uma grande anunciante do 
Diário, eu não tinha problema de publicar matéria gratuita deles, mas a GM, por exemplo, era anunciante. O jornal sempre viveu muito do anúncio.

E a sua saída - já era o Diário -, teve algum motivo?

Não, minha saída foi assim: eu estava ativa, trabalhando, e para me casar, não estava marcado ainda o casamento, pois eu saí em 1969, numa época de muito aperto de dinheiro para a gente. Nós compramos apartamento, tínhamos que mobiliar, aquela coisa toda que você sabe, em qualquer época é difícil. E eu tive uma oferta da companhia telefônica para ser secretária da divisão financeira da Telefônica, porque o doutor Martins e o senhor Oliver Tognato me conheciam muito do Diário, eles eram amigos, a gente estava sempre junto, eu era amiga das famílias. Eles faziam parte do Rotary e tudo que tinha do Rotary eu estava lá fazendo a cobertura. Tinha muita matéria, porque o Rotary e o Lions Clube foram muito importantes em Santo André. A gente dava cobertura o máximo que podia, pois eles fizeram coisas brilhantes: o Rotary fundou a Casa da Esperança, que até hoje é uma coisa maravilhosa, e o Lions fundou um hospital infantil, Faisa [Fundação de Assistência a Infância de Santo André]. Então era um pessoal muito querido, e a gente tinha amizade. O senhor Oliver Tognato e o doutor Martins me chamaram para ir trabalhar lá na divisão financeira, pois a Telefônica estava lançando o famoso Plano 70, que era para instalar telefone em todo lugar na região do $\mathrm{ABC}$, em todos os lugares. Eles formaram uma equipe de gente que consideravam muito boa, porque era um grande passo, enorme, muito arriscado; se não desse certo, a Telefônica faliria. Eles procuraram pessoas de vários setores da sociedade que eles conheciam, para chegar lá e deslanchar. Eu fui escolhida para ser a secretária do diretor financeiro, e me ofereceram três vezes mais do que eu ganhava no Diário. Aí eu tentei conciliar as duas coisas, conversei com Fausto Polesi e fui para a Telefônica, me dei bem lá, mas continuei fazendo a minha página, já que era só aos domingos.

\section{E tinha uma notinha diariamente.}

É, tinha uma notinha diariamente, mas era tranquilo, só que chegou a um ponto que não deu, pois aí o tal Plano 70 estourou, foi o maior sucesso, colocou telefone na casa de todo mundo, e eu não pude continuar com o Diário. Como eu poderia abrir mão de um salário que era três vezes mais do que eu ganhava no Diário? Com um monte de regalias: plano de saúde, que o Diário não dava, pois naquele tempo não era obrigatório. Então, como eu estava para me casar, a gente precisava muito de dinheiro, conversei, e o Sidney [noivo de Eulina] falou para mim: "Não tem nem escolha, você tem que ficar com a Telefônica, você tem que ver onde entra mais dinheiro". E aí me desliguei do Diário, mas continuei amiga deles a vida toda, acabei sendo vizinha do Edson Dotto, lá no bairro Campestre, e era um entra e sai na casa um do outro. Eu vi as crianças dele crescerem, eu dava aula particular de história para as crianças, pois eu sou professora de história.

\section{E aí, quando você saiu, eles tiraram o "Ela", pois mudaram o nome.}

Tiraram o "Ela", pois mudou o nome, e a Ana Regina passou a assinar, acho que era uma página, não é? 
Ficou a mesma coisa, só o nome que trocou: umas notinhas todos os dias e uma página aos domingos, mas passou a se chamar "No mundo de Eva".

Ela era muito menina, tinha 16 anos, sem experiência nenhuma de vida. Como é que uma menina de 16 anos vai escrever um artigo falando de família? Ela não tinha "cancha". Na verdade o Diário foi pego de surpresa com a minha saída, talvez nunca contassem com isso, mas chega uma hora na vida que você tem que fazer opções, tem que fazer o que é melhor para você, não o melhor para os outros. E foi a questão financeira que pesou. Na época a Telefônica me pagou um ordenado que deixava todo mundo para trás.

E você poderia falar mais um pouquinho sobre o "Ela"? Tinha cartas dos leitores, a que você respondia, a grande maioria sobre a temática de saúde.

Era eu quem respondia às cartas. Muito interessante, era uma troca gostosa, muita gente telefonava, a gente conversava por telefone, batia papo, explicava, tinha gente que me ligava e falava: "Você publicou uma vez uma receita de torta de bacalhau que era uma delícia, e eu perdi a receita, não dá para você publicar outra vez?" E eu lá ia lembrar da receita da torta de bacalhau, quando tinha sido?... Aí eu tinha que pesquisar nos jornais todos para ver onde estava a tal receita para agradar a mulher. A preocupação da gente naquela época era agradar o leitor. Isso era um ponto fundamental do Diário, pois essa era a fonte de renda, as assinaturas do jornal. Então, tudo que pediam, a gente fazia, às vezes até saía cada reportagem boba, mas era um leitor que tinha pedido, e a gente fazia a reportagem. Era muito provinciano. Santo André era uma cidade de interior, como uma cidade de interior é hoje. Santo André era isto: as pessoas todas se conheciam, você tinha tempo para tudo, e a gente prestigiava muito; tudo que pediam a gente procurava acatar. É muito interessante, nesse período em que o suplemento Ela foi suspenso e ficou sendo uma página dominical e mais um trechinho todos os dias, eu assumi outras funções no Diário. Fazia todo tipo de reportagem, cheguei até a fazer reportagem policial, porque era assim, o redator não estava, mas eu estava lá naquele momento, chegava uma notícia, teve um incêndio não sei onde, teve um acidente não sei onde, o Diário me mandava, e eu ia. A gente fazia tudo. Só nunca escrevi sobre futebol, porque também não entendo bulhufas, mas se precisasse, até era capaz de escrever, pois alguém tinha que fazer. E tinha os plantões: você ficava de plantão no jornal no domingo, qualquer coisa que acontecesse você tinha que ir lá com o fotógrafo e fazer a cobertura, fosse o que fosse.

Para finalizar, como você lidava com as matérias femininas, pois me parece que você falava coisas tradicionais e colocava no meio pitadas de emancipação feminina; era algo deliberado?

Eu sempre procurava colocar alguma coisa da liberação feminina, do feminismo que estava no auge: a Betty Friedan lá dos EUA, aquela história de queimar sutiã, aquela coisa toda. $\mathrm{O}$ feminismo estava no auge, e eu gostava muito, claro, eu sempre gostei muito de liberdade, então a gente começava um artigo com uma conversinha macia e depois jogava alguma coisa de feminismo, para não ficar tão ostensivo que era um artigo feminista, mas era. 


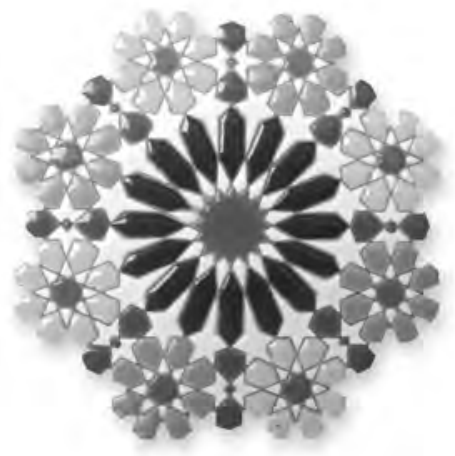

